\title{
Result of Review
}

\section{International Journal of Health}

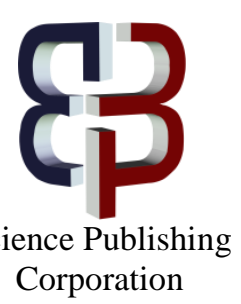

Title: Relationship between Sleep Disturbances in Late Pregnancy on Labor Outcomes

Author(s): Dr. Aida Abd El-Razek. Gamila Ayoub. Abdul-Monim Batiha. Fadwa Alhalaiqa.

Hoda Farahat Mohammed ALBashtawy

\section{Decision of Paper Selection}

( ) Accept submission, no revisions required

(*) Accept submission, revisions required

( ) Revise and resubmit for review

( ) Decline submission

\section{What should you do?}

- Revise the paper according to the comments and resubmit it by email.

- Write a detailed email on replying the review report explain how you edited your paper to meet the reviewer comments. 


\section{Review Comments}

\begin{tabular}{|l|c|}
\hline \multicolumn{1}{|c|}{ Evaluation } & $\begin{array}{c}\text { Grade } \\
\text { 5=Excellent } 4=\text { Good 3=Average } \\
\text { 2=Below Average 1=Poor }\end{array}$ \\
\hline Overall evaluation on the paper & $\mathbf{3}$ \\
\hline Originality of the paper & 4 \\
\hline Significance & 3 \\
\hline Contribution to existing knowledge & 3 \\
\hline Clarity of presentation & 2 \\
\hline Adequacy of literature review & 3 \\
\hline Soundness of methodology & 3 \\
\hline Evidence supports conclusion & 3 \\
\hline
\end{tabular}

\section{Comments and Suggestions}

It is an interesting paper, well written but it needs some modifications to be ready for publication.

- The English must be carefully checked.

- Similarity index (checked by iThenticate) is high, please revise to make it lower (source matches are not $>15 \%$ ).

- More references should be found and they should cover the last 5 years.

- Add DOI persistent links to those references that have DOIs, please retrieve Digital Object Identifiers (DOIs) at http://www.crossref.org/SimpleTextQuery/

- Lastly, the references should be made according to the journal format.

I recommend accepting the paper after the modifications suggested have been incorporated.

Please make substantial changes in the revised version and resubmit it again, provide authors' respond to the comments. 